University of Wollongong

Research Online

Faculty of Business - Papers (Archive)

Faculty of Business and Law

2013

Innovative ICT-mediated activities for people, profit and planet

Helen Hasan

University of Wollongong, hasan@uow.edu.au

Joseph Meloche

North Carolina Central University, jmeloche@uow.edu.au

Follow this and additional works at: https://ro.uow.edu.au/buspapers

Part of the Business Commons

Research Online is the open access institutional repository for the University of Wollongong. For further information contact the UOW Library: research-pubs@uow.edu.au 


\title{
Innovative ICT-mediated activities for people, profit and planet
}

\begin{abstract}
Purpose - Solutions to complex environmental problems rely on the innovative knowledge and expertise of many professions whose members accept their responsibilities towards the environment. The study described here canvases Information Systems (IS) professionals for their perspectives, knowledge and expertise within the domains of Green IT and Green IS.
\end{abstract}

Design/methodology/approach - Following a review of the Green IT and IS literature, two topics were identified for a Q-study conducted among IS professionals: Topic 1 focussed on which technologies, systems and applications offer the greatest opportunity in solving environmental problems, and Topic 2 on what sets of issues affect these green opportunities. Activity Theory was used to interpret the factors emerging from the Q-study.

Findings - Three categories of activities were identified on Topic 1 involving ICT support for "teleworking and teleconferencing", "monitoring, optimising, and modelling" and influencing human understanding and behaviour". The Topic 2 responses were quite varied.

Research limitations/implications - A Q-study is both subjective and exploratory not seeking consensus but rather the breadth of opinion on a topic. The findings on topic 1 indicate three directions for future research and topic 2 identified many issues to consider in pursuing Green outcomes.

Practical implications - The varied issues identified on Topic 2 reveal the interconnection of environmental projects with economic and social issues.

Originality/value - Following this study of IS professionals we call on other professions to consider applying the expertise of their respective fields to the environmental cause.

\section{Keywords}

profit, people, activities, planet, mediated, innovative, ict

\section{Disciplines}

Business

\section{Publication Details}

Hasan, H. \& Meloche, J. (2013). Innovative ICT-mediated activities for people, profit and planet. European Journal of Innovation Management, 16 (3), online. 


\section{Innovative ICT-Mediated Activities for People, Profit and Planet}

\begin{tabular}{|l|l|}
\hline Dr Helen Hasan & Dr Joseph Meloche \\
Associated Professor in Information Systems & Assistant Professor \\
School of Economic, & School of Library and Information Sciences \\
Faculty of Commerce & North Carolina Central University \\
University of Wollongong & P.O. Box 19586 \\
Northfields Ave & Durham, North Carolina \\
Wollongong, NSW 2522 & USA. \\
Australia & Email: jmeloche@ nccu.edu \\
Email: hasan@uow.edu.au & \\
\hline
\end{tabular}

\section{Abstract}

Purpose: Solutions to complex environmental problems rely on the innovative knowledge and expertise of many professions whose members accept their responsibilities towards the environment. The study described here canvases Information Systems (IS) professionals for their perspectives, knowledge and expertise within the domains of Green IT and Green IS.

Design/methodology/approach Following a review of the Green IT and IS literature, two topics were identified for a Q-study conducted among IS professionals: Topic 1 focussed on which technologies, systems and applications offer the greatest opportunity in solving environmental problems, and Topic 2 on what sets of issues affect these green opportunities. Activity Theory was used to interpret the factors emerging from the Q-study.

Findings: Three categories of activities were identified on Topic 1 involving ICT support for "teleworking and teleconferencing", "monitoring, optimising, and modelling" and influencing human understanding and behaviour". The Topic 2 responses were quite varied.

Research limitations/implications: A Q-study is both subjective and exploratory not seeking consensus but rather the breadth of opinion on a topic. The findings on topic 1 indicate three directions for future research and topic 2 identified many issues to consider in pursuing Green outcomes.

Practical implications: The three Topic 1 categories of activities identify practical 'green' applications of ICT.

Social implications: The varied issues identified on Topic 2 reveal the interconnection of environmental projects with economic and social issues.

Originality/value Following this study of IS professional we call on other professions to apply the expertise of their respective fields to the environmental cause.

Keywords: Green Information Systems; Activity Theory; IT Innovation; Q-methodology.

\section{Introduction}

Information and communications technologies (ICT) are driving a continuing evolution of innovation for all human activities, transforming the ways we do things at home, at work and in the larger society. However, the use of ICT consumes energy, and energy production 
releases Green House Gases (GHG), which are a major cause of global warming and potentially damaging climate change (IPCC, 2012). While there is an imperative to limit GHG emissions, simply turning off the technology is not an option. We need to look for ways to limit the emissions caused by ICT use (popularly call the "Greening of IT" or simply "Green IT"). We should also seek ways to use ICT to reduce the harmful environmental and social impacts of all human activity (popularly call the "Greening by IT"). Researchers in Information Systems (IS), a field which addresses the human and organisational issues associated with ICT, take the latter approach and see "Green IS" as their responsibility.

The research presented in this paper is based on the premise that most of the Green IT and IS literature has a narrow focus on the Carbon Footprint of things, a focus which ignores the purpose for which these things are used. In this paper we take a broader view and focus on the Carbon Footprints of contextual activities and thus turn to Activity Theory (Leontiev, 1981) for an understanding of how tools such as ICT mediate cycles of human activities. Activity Theory allows a realistic and holistic understanding of emerging phenomena by distinguishing purposeful activity from more routine actions toward specific goals that contribute to that purpose (Leontiev, 1981). It thus supports a holistic perspective which can be used to address wicked problems such as climate change and other complex environmental challenges so that more innovative solutions can be found. This holistic perspective is particularly appropriate when solutions affect the whole triple bottom line of social, economic and environmental analysis (Brown et al., 2006) popularly known as people, profit and planet.

The dominant message of current Green IT thinking is negative, with ICT viewed as a significant contributor to harmful emissions. Green IS promotes the counter argument that with ICT usage we have the potential and opportunity to positively influence the global environmental future (Ghose et al., 2008) Watson, Boudreau and Chen (2010) present a call to arms for IS to address environmental sustainability. "Specifically as IS researchers, educators, journal editors, and association leaders, we need to demonstrate how the transformative power of IS can be leveraged to create an ecologically sustainable society," (p. 23). This has been echoed in the work of Melville (2010) and Elliot (2011).

Solving wicked problems requires knowledge and expertise from many disciplines. The research presented here aims to make sense of the responsibilities of the IT/IS community in facing the confusing array of elements in the challenges posed by climate change. We thus propose the following research questions:

1. By means of what activities, do IS professionals believe they can readily contribute to the reduction of climate change?

2. What can a focus on activities rather than things add to the Green IT/IS literature?

The paper begins by positioning this challenge in the emerging literature on Green IT and Green IS. It then describes a Q-study on two topics: (1) the technologies, systems and applications that offer the greatest opportunity in solving problems concerned with the environment; and (2) the sets of green issues that affect these opportunities. This follows the example of others who have also chosen Q-methodology for exploratory studies of environmental issues (e.g. Barry and Proops 1999). The results of this study are interpreted through the concepts provided by Activity Theory to determine ICT mediated activities that are likely to provide an innovative and holistic way forward. 


\section{An overview of the Green IT/IS literature}

To underpin our answers the research questions we present an summary of the literature with which many of our participants were familiar. This provides a framework within which to understand the activities identified in response to the first question. It also provides evidence for our proposition that the focus of current Green IT research is on things and that a focus on activities is a prudent basis for current and future Green IS studies.

\subsection{Green Issues and IT}

The topic of climate change has held centre stage on the international arena in recent years fired by the release of the Stern Report in the UK (Stern, 2006) and the Al Gore documentary, An Inconvenient Truth (Gore, 2006). However in the many government and community communications on Climate Change and Green House Gas (GHG) Emissions, there is surprisingly little mention of ICT, except when the topic is specifically Green IT. The public spotlight is on controversies surrounding the science as well as the viability and costs of engineering solutions that provide clean energy. Much of what is written on ICT related matters in the public arena tends to be optimistic. Buried in the Stern report is an assertion that innovations embodied in IT have played a key role in reducing energy intensity over the long term (Stern, 2006). Romm and colleagues (1999) also reported the Internet as an element in reducing energy intensity, predicting that $e$-materialisation of paper, construction and other activities could reduce GHG emissions by $1.5 \%$. Widely quoted within the IT industry, however, is the Gartner estimate that the global ICT industry accounts for approximately $2 \%$ of global carbon emissions, a figure they believe is unsustainable (Gartner, 2007). The Gartner report does however acknowledge the overall environmental value of IT.

The conventional wisdom of the popular literature on climate change advises us to "think global and act local". Many of the activities where we can do things through ICT have both dimensions: the global, though the Internet, and our local use at work and at home. Through the drive to regulate, national interests also have prominence. Here in Australia, there was a rapid acceleration of relevant government initiatives in 2008, which are framing unprecedented public debate. Our ratification of the international Kyoto Protocol on Climate Change (DCC, 2008) was the first priority of the new Labor Government when elected in 2007. A National GHS and Energy Reporting Scheme came into effect on 1 July 2008 and the federal parliament is currently debating a bill to introduce an Emissions Trading Scheme (ETS). This government policy was guided by the Garnaut Climate Change Review (Garnaut, 2008) which released its Final Report on 30 September 2008 following the Draft and Supplementary Draft Reports released in June 2008. The public Green IT message has been dominated by the view of IT as a large user of energy resources and hence a significant contributor to GHG emissions.

The public focus is on the technology, i.e. "things" and only marginally on the "activities" that are supported and enabled by the technology as evident in the following review. We now turn to business to investigate the focus there through industry associations and firms themselves.

\subsection{Green IT in Business}

On the global ICT front, one ready source of industry publications on the topic of Green IT comes from IT associations (e.g. ACS, 2007), magazines (e.g. CIO, 2008) and the multinational IT firms who demonstrate an acute awareness of its impact on their business (e.g. Fujitsu, 2011). The Green Grid (www.thegreengrid.org) is a global consortium of such firms founded in February 2007 by several key companies in the industry. Its current board 
has as constituents: AMD, APC, Dell, HP, IBM, EMC ${ }^{2}$, Intel, Microsoft, and Sun Microsystems while VMware and Google are noted general members. The Green Grid is focused on improving data centre and general computing efficiency through the use of metrics and measures, such as Power Usage Effectiveness (PUE) and Data Centre Efficiency (DCE). It promotes standardised reporting of such measures although those outside the grid are sceptical that this standard is inherently biased towards its members. They see that creating a green image is good for business. Most have prominent links to their Green IT initiatives on their websites, eg Microsoft's GreenIT site, IBM's GreenerComputing HP's Global Citizenship Program.

In addition to firms within the IT industry, most large companies are keen to reduce, and be seen to reduce, their Carbon Footprint, including that of their computing infrastructures and applications. For example Wal-Mart, the US retail giant, has developed a worldwide Sustainable Product Index (http://walmartstores.com/FactsNews/NewsRoom/9277.aspx) to measure the environmental costs that go into the creation of Wal-Mart's products. Suppliers will be asked to complete a survey of questions determining the environmental impact of their products and company. The index will influence Wal-Mart's choice of products and presumably consumers purchasing decisions. Locally, the largest Australian Telecommunication's company, Telstra, makes prominent on its website its efforts on carbon emissions (http://www.telstra.com.au/abouttelstra/csr/environment/climate_change.cfm) and uses this as a marketing tool.

Motives driving this trend range from genuine concern for the planet to the business benefits of having a green image. In some cases, firms are accused of greenwashing, a term that is used to describe the act of misleading consumers regarding the environmental practices of a company or the environmental benefits of a product or service (stopgreenwashing.org). In other firms there appears to be a revival of interest in the concept of the triple bottom line and the need to look for solutions that integrate and improve corporate, social, environmental and economic performance (Brown et al., 2006). We now look at what the academic research is saying on this topic.

\subsection{Green IT Research}

Publication of research that is more rigorous, objective and comprehensive on the subject of Green IT is beginning to appear in diverse areas of the trade and academic literature.

Two definitions of Green IT are:

"the conscious implementation of technologies, techniques and policies designed to reduce the Carbon Footprint of the IT function within the organisation... and the use of IT to reduce the Carbon Footprint of the whole organisation." (Phillipson, 2009)

"the study and practice of designing, manufacturing, using, and disposing of computers, servers, and associated subsystems - such as monitors, printers, storage devices, and networking and communications systems-efficiently and effectively with minimal or no impact on the environment. Green IT also strives to achieve economic viability and improved system performance and use, while abiding by our social and ethical responsibilities." (Murugesan, 2008)

Several studies deal with organisational motives and reasons for Green IT. Elliot (2007) identified the presence of competitive, legal and social responsibility dimensions of motivational elements influencing Green IT within organisations. Sayeed and Gill (2008) identified through a series of interviews that the main reasons given for undertaking Green IT initiatives were cost cutting and energy conservation. An empirical study by Kuo and Dick 
(2009) suggests that Green IT efforts are motivated by employees' sense of social responsibility within organisations that have the capability to adapt rather than by issues of economics and technologies. Molla (2008) developed a Green IT Adoption Model where motives corresponded to the economic, regulatory and ethical drivers of Green IT. Other researchers have created similar models from theory and secondary data (Daly and Butler, 2009; Bose and Luo, 2011). Elliot and Binney's (2008) case study suggests the influence of government reporting, regulation and customer demand are potential drivers for Green IT and found that responsiveness to staff concerns and client requirements were also reasons for engaging in Green IT. (Elliot and Binney 2008, p. 8). In a comparative study Molla, Pittayachawan and Corbitt (2009) have produced comparative data on Green IT and organisational sustainability. They identified energy efficiency and cost cutting as the primary consideration of US organisations, whereas organisations in Australia and New Zealand seem to be primarily motivated by environmental considerations.

Another group of studies concern the positive impact of Green IT on social, environmental and economic indicators in organisational systems (Velte et al., 2008; Caldille and Parmigiami, 2004), in e-business (Yi and Thomas, 2006) and across the supply chain (Rao and Holt, 2005). A cross organisational study by Phillipson (2009) is leading towards the development of a Green IT Readiness Index, a measure of the level of maturity of an organisation's usage of Green IT in five key areas: End User Efficiencies, Enterprise IT Efficiencies, Lifecycle and Procurement, Measuring and Monitoring, and Enabling the Business. This draws on the concept of e-readiness (Molla and Licker, 2005; Berthon et al., 2008).

Several of these reports are ambivalent about the positive and negative green aspects of ICT. Koehler and Erdmann (2004) say that Pervasive Computing will bring about both additional loads on, and benefits to, the environment. Berkhout and Hertin (2004) argue that the diffusion and use of ICTs are leading to both positive and negative environmental impacts. They also observe that because the effects of ICTs on economic activity are pervasive, their impacts on the environment are difficult to trace and measure. Fuchs (2008) while recognising potential in the relationship between ICT and sustainable development attacks some popular myths about a sustainable information society such as the expected benefits of tele-work and the unquestionable ability of virtual products to allow resource, energy, and transport savings.

\subsection{Green IS}

We now turn to the distinctively IS literature where one would expect less focus on technology. Boudreau, Chen and Huber (2008) distinguished Green IS from the more widely used term Green IT by saying that Green IT is seen as a major contributor to GHG emissions and takes a negative view of IT as an energy consumer. Green IS, in contrast, is described as "the design and implementation of information systems that contribute to sustainability of business processes" tackling a much larger problem in a positive and valuable manner.

The positive Green IS message can be found in the work of Fuhr and Pociask (1999), who report on a study determining reduction in GHS emissions through the wide delivery of broadband services in the US and more recently the work of Fernandez and colleagues (2008) on how IS design can support and coordinate a project to extract oil from green algae. This message is also driven home in the Smart 2020 project (GeSI, 2008), a UN media release (UN, 2007) and the CCCI report (Ghose et al., 2008, p1) which promotes the notion that "we live in a massive, inter-connected Planet Earth Supply Chain and IS provides a range of tools to model, manage and optimize this supply chain". 
Chen, Boudreau and Watson (2008) have developed an insightful conceptual model that clarifies the roles of IS in the pursuit of ecological sustainability. Their findings show how, under different institutional pressures, IS can be leveraged to achieve eco-efficiency through automating, eco-equity through information flows and eco-effectiveness through organisational transformations. The work of Daly and Butler (2009) also takes an IS perspective using Institutional Theory to develop a set of theoretical propositions which specify the effect that regulatory, normative and cultural-cognitive elements have in shaping environmental responsibility in organisations.

The literature most supportive of a positive view of Green IS, is a series of papers presented at the Workshop on Ubiquitous Sustainability (Hasbrouck et al., 2007). These papers demonstrate an understanding of emerging practices through which technologies are able to align with environmental values. Many of the papers presented ways of designing innovative but often quite simple systems to influence behaviour towards greener outcomes. These included ways to sense and display energy consumption and other carbon emitting events in the home (LeBlanc, 2007; Brush, 2007; Stringer et al., 2007), at the office (Bray, 2007) and in the town (Hooker et al., 2007; Ljungblad, 2007). Greener actions and uses of technologies have been shown to increase by providing information incorporated in stories (Oehlberg et al., 2007) and by playing games (Millecevic, 2007). While the emphasis is on 'systems' rather than 'things' it still does not talk about 'activities' as such.

In a seminal paper on Green IS, Watson, Boudreau and Chen (2010) explore ways to develop environmentally sustainable business practices through the use of "energy informatics". Two other prominent IS articles (Melville, 2010 and Elliot, 2011) include comprehensive reviews of the literature that recognize the value of the holistic and trans-disciplinary nature of Green IS research. Our research takes evidence from the subjective opinions of IS professionals in order to complement the existing literature.

\section{Research Design and Background to the Study}

The Literature Review demonstrates the breadth rather than any great depth in the study of Green IS issues. The design of the study described was chosen to help make some sense of this breadth as follows.

\subsection{Q-methodology}

Q Methodology was selected as the technique for data collection and analysis in this exploratory study to enable us to better understand the range of views on the two chosen topics by a group of knowledgeable participants. This method is particularly suitable for a topic having complex ramifications that are not yet well understood. It is significant that the Q Methodology is designed to uncover the range of views, attitudes, opinions, understandings and experiences on a specific topic of investigation, as opposed to most methods that offer one composite view. Q Methodology consists of procedures for data collection and analysis that reveal communicative subjectivity on a topic. It gives a voice to understandings of key issues and enables the people involved to share their views and opinions in a structured way (Brown 1986). This approach can help to expose aspects of issues which may otherwise be invisible and not anticipated by the researcher. A Q-sample of 20 to 50 participants has the ability to produce meaningful results i.e. provide an accurate picture of the range of views on a topic (McKeown \& Thomas 1988).

As indicated in the Barry and Poops (1999) Q-study on sustainability, Q Methodology is conducted in six stages: Stage 1 is the selection of the topic; Stage 2 the collection of statements on the topic; and Stage 3 the refinement of these statements into the Q sample; 
Stage 4 involves the sorting of the statements in the Q-sample by individual participants in the study; Stage 5 is a factor analysis of the sorts; and Stage 6 the interpretation of the resulting Factors. Because of the factor analysis in Stage 5, Q Methodology has been frequently associated with quantitative forms of analysis. However, as it deals with people's subjective opinions, the interpretation of the factors has the richness of the qualitative method in particular Stages 1, 3 and 6 performed by the researchers.

In this Q-study we performed Stage 2 with a concourse, which involves having the participants provide their thoughts and views on a topic as short statements. This set of statements was not generated in a single session but transpired over time and amongst various groups, but were always on the same topic.

The Q-sort in Stage 4 involves eliciting the individual views of participants as they each rank the set of statements reflecting the extent of their agreement or disagreement with them. The statements are numbered, and sorters are given a grid such as the one in Figure 1 where there is one box for each statement. The largest number of statements will be placed in the centre with far fewer at each extreme side, forcing sorters to give some thought to the choice of a small subset of statements that they ranked high and low (Meloche and Crawford, 1998).

The Q Sorts for all the sorts are statistically analysed by any of the standard Q factor analysis computer programs to find correlations and identify Factors that are common to the sorts of several individuals (Stephenson, 1953). The resulting Factors are clusters of those individuals who appear to hold similar views in their ranking of the statements, particularly the few statements ranked highest and lowest.

\subsection{Activity Theory}

The Cultural Historical Activity Theory (Activity Theory) has its roots in the work of the Russian psychologist, Lev Vygotsky, whose observations on the dynamics of consciousness showed that it is essentially subjective and shaped by the history of each individual's social and cultural experience (Vygotsky, 1978). Vygotsky defined human activity as a dialectic relationship between subject and object, i.e. a person or subject working at something, the object. In this dynamic, purposeful relationship the 'always active' subject learns and grows while the object is interpreted and reinterpreted by the subject in the ongoing conduct of the activity (Hasan and Crawford, 2006). In addition, Vygotsky saw object-oriented human activity as quite distinct from that of non-human entities in that it involves the use of tools, the most significant of which is language. Vygotsky believed that tools play a mediating role in all human activities and mental processes which can only be understood in terms of the tools and signs that mediate them (Verenikina and Gould, 1998). This is a two-way concept of mediation where the capability and availability of tools determine how the activity is able to be done, and tools in turn evolve to improve the way the activity can be performed. This is particularly powerful when the tools are computer-based (Kaptelinen, 1996). In the conduct of activities, intended and unintended outcomes are produced as shown in Figure 2.

Activity Theory itself emerged from the work of Vygotsky's students, in particular Luria (1976) and Leontiev (1981). Luria (1976) showed that human psychological functions could be transformed under the influence of changing psychological tools. Leontiev (1981) developed Vygotsky's ideas of social and cultural mediation by developing a hierarchical model of human activity (Figure 3). According to Leontiev (1981), activity is a system that has structure, its own internal transitions and transformations, and its own development. Participating in an activity involves performing a set of conscious actions that have an immediate and definite goal. Just as activities are always related to motives, actions are always related to goals. The one activity could be performed by different sets of actions. For 
example, classes can be variously taught through lectures, workshops, e-learning and many other actions. Although goals are always conscious, the operations which make up actions are usually non-conscious involving tasks that are performed more or less automatically, for example typing up notes using a word-processor. Most importantly, although an activity can consist of many actions and operations, it is dynamically embedded in its context and so is more than the sum of these.

The hierarchical structure shown in Figure 3 is dynamic. Leontiev used the example of learning to drive a manual car. He observed that, for the novice sitting in a stationary car, changing gears may be a purposeful activity. It becomes a conscious action as the learner takes to the road and then an unconscious operation for the experienced drive. However if something goes wrong, in this example some gears are stripped, changing gears again becomes a challenging action that required conscious attention.

Three kinds of tools mediate human activity (Hasan 1998):

— Primary Tools: $\quad$ artefacts, instruments, machines, computers etc

- Secondary Tools: language, signs, ideas, models etc

- Tertiary Tools: cultural systems, environments, contexts, communities, virtual spaces etc

Primary tools are physical, material tools, secondary are psychological and tertiary tools are social tools. While primary tools produce changes in the material object, psychological tools influence the psyche and behaviour of subjects (Verenikina and Gould, 1998) and social tools set boundaries on activities due to the culture, environment and context (Hasan 1998). Digital technologies can provide examples for all of these. The computer itself, and many of its standard applications, are basically primary tools allowing us to produce documents, images and videos. However the thesaurus, for example, is more of a secondary tool supporting our thinking. The Internet with its connectivity and social media are tertiary tools supporting a variety of disparate virtual communities.

Following the pioneering work of Engeström (1987) and Kuutti and Virkkunen (1995), Activity Theory is used to underpin this research by taking activity as the unit of analysis. Activity is a Russian translation of deyatelnost denoting a high-level, long-lived construct unlike frequent common uses of the word in English. Each activity is identified through the dialectic relationship between subject and object where the object encompasses focus and purpose while the subject, a person or group engaged in the activity, incorporates the various motives involved. While the core of an activity is the subject (human) and object (purpose), this relationship is always mediated by tools, primary, secondary and tertiary. Where some activities have individual subjects, a project team would be a collective subject composed of a group of individuals who bring different skills and understandings to bear on the project whose purpose, as the team interprets it, is the common object.

The richness of this notion of activity is exemplified by its basic definition as a dialectic relationship between the subjective and objective elements of what is done (Vygotsky, 1978). This means that there are inevitable contradictions between interconnected activities and between different motives for the one activity (Engeström, 1987).

\section{The Q-Study}

We put together a professional reference group of 20 participants comprised of practitioners, academics and students who were specifically chosen for their familiarity with IS and/or ICT 
and concerned with green issues. After some lengthy discussion, the group identified two critical topics relevant to Green IT and IS that would be suitable for a Q-study.

Topic 1 Technologies, Systems and Applications of ICT that fall under the Green IT/IS umbrella (i.e. can be used to enable, support, encourage, monitor etc activities that reduce the Carbon Footprint of organisations and individual, that mitigate against climate change and generally have positive outcomes for the environment).

Topic 2: Issues and challenges to be faced in promoting and implementing the Technologies, Systems and Applications listed in topic 1.

The Concourse: Two sets of statements on the two topics were elucidated through several meetings of the participants and through circulating the growing sets of statement by email. This evolutionary process produced duplicate statements that were eliminated and the wording of some statements clarified. This resulted in two set of statements examples of which can be seen in Tables 3, 5 and 6 .

The Sort: The individuals who participated in the concourse, together with three other IS experts, were invited to do the two sorts, making a total of 23 participants (see Table 1). Instructions for the sorts were as follows:

Topic 1: Rank these statements on the way you would prioritize these technologies, systems, initiatives, processes etc for implementation taking into account both their positive impact on the environment (reduction in Carbon Footprint etc) and their ease of implementation (cost, acceptance etc) i.e. their position as "low hanging fruit" and which ones you would least prioritize. IT is used as a generic term including ICT and IS. If the statement does not make sense to you rank it in the middle of the grid.

Topic 2: Rank these statements on how you view their importance to the role of IT, and the IT community, as a source of solutions to the climate change problem. IT is used as a generic term including ICT and IS. If the statement does not make sense to you rank it in the middle of the grid.

A varimax factor analysis was performed using standard Q-method software on each of the two sets of 20 sorts. The findings are as follows.

\subsection{Outcomes on Topic 1}

As summarised in Table 2, a 2-Factor solution accounts for 13 sorts was selected within which there are 14 consensus statements (statements similarly ranked) out of 35, as shown in Table 3. As shown below, the second factor was bipolar, i.e. five of the six sorts loaded positively on this Factor having ranked the statements in similar manner and one was the reverse of these having loaded negatively on the Factor. This gave 3 clusters of opinion, with seven people loading on Factor 1, five people loading on Factor 2 and one person on Factor $2 \mathrm{~b}$ (the bipolar part of factor 2).

The seven people on Factor 1 placed "Telecommuting and Teleconferencing" as their top choices taking into account both their positive impact on the environment and the practicalities of implementation. Lowest rankings were for RFIDs and other embedded devices.

Five people on Factor 2a gave the following statements high ranking: "systems for optimization of $\mathrm{CO} 2$ emissions"; "long-term monitoring of climate to quantify the changes"; "long-term predictions of capturing carbon from atmosphere and storing it"; "optimization technologies for efficiencies of systems (transport etc)"; and "global and regional climate modelling". This group ranked "visualisation of information" the lowest. One person on Factor $2 \mathrm{~b}$ (sort 11 - a mature aged undergraduate student) took the opposite view. 


\subsection{Outcomes on Topic 2}

There was a much less coherent message on Topic 2 where a 4-Factor solution involved 13 sorts as shown in Table 4. Factors 1 and 4 were bipolar, as each had 1 sort that was the exact opposite of the others. This gave 6 different viewpoints with small numbers on each. There were only 3 consensus statements across the four Factors as shown in Table 5. Two statements, namely: "legal issues, rules, guidelines or laws" and "legislation and taxation influencing factors" were ranked highly ( 2 or 3 ) by all Factors and the statement "interpreting the science" was seen as neutral (i.e. not an issue - no climate change sceptics among them).

\section{The Activity Theory Interpretation}

The results of the Q-study are now reinterpreted using activity as a high level unit of analysis and referenced back to citations of these activities in the literature review in Section 2 of the paper. The three Factors identified in Topic 1 lend themselves to this quite well while the six Factors of Topic 2 are less distinctive. Activities association with Factors are identified in this section of the paper by their purpose through the subject-object relationship (who is doing what and why). Each activity is then understood in terms of actions and operations as mediated by three levels of tools: physical, psychological and social. The concept of tool mediation implies that an activity is enabled by the tools and in turn influences future tool development. This is particularly powerful for understanding the dynamic nature of tertiary tools in the current climate of globalisation. The cultural aspects of a community can determine what can be done by whom, but the outcomes of a virtual activity can subsequently alter the culture, broadening its world view.

\subsection{Topic 1}

Three activities are identified from the Factors of Topic 1 as follows:

\subsubsection{Factor 1 Activities of communication, collaboration and co-ordination}

Factor 1 consists of a group of 7 people who ranked teleconferencing and tele-working as practices with the most potential to easily improve the environment. These practices relate to the activities of teams and groups of people working together at a distance (ie virtually) through acts of communication, collaboration and co-ordination. As can be seen in the Topic 1 column of Table 1, the majority of the group on this factor were students or practitioners, probably not having had much experience of either practice, but particularly not with teleworking. This finding confirms that these ways of working are popularly seen as good for the environment. Indeed, it is generally assumed that tele-working reduces travel and hence lowers, but does not eliminate, their Carbon Footprint. However, as noted in the Literature Review above, tele-working has not been adopted in the workplace to the extent that has been expected. Activity Theory would suggest that this may be because those involved, management and workers, have not properly understood the motives for activities of teleworking, and the available tools have not adequately supported the purpose of these activities. There is some recent evidence that interest in tele-working is receiving renewed attention from business and government in Australia (Deloitte 2011) where a renewed focus on the environment recognises the Carbon Footprint of commuting to work and the rolling out of a high-speed broadband network across the country is improving the capability of tele-working tools.

The work activities associated with these tools involve performing work that is comprised of holding meetings, coordinating teams and otherwise collaborating at a distance. Teleconferencing could be considered as a primary tool supporting actions of holding meetings and tele-working a tertiary tool providing a virtual context of work. In Activity 
Theory it is the activity not an action or the tool that is the unit of analysis. In the case of teleconferencing, the purpose associate with a meeting is rarely just to hold a meeting. A meeting is most likely to be an action not an activity and an action should have a goal that aligns with the purpose of some meaningful activity. For example, it is not just enough to say that it is cheaper, easier, better for the environment to hold a teleconference than to fly several people to another city for a project team meeting. If the teleconference meeting is awkward and has no useful outcomes for the project team, it has generated an unnecessary Carbon Footprint. Activity Theory would recommend that the goal of the action (the meeting) be made explicit, in the context of the relationship between the purpose of the project (the object of the activity) and the people involved (the subjects of the activity). The tool that could best mediate a particular meeting (travel or teleconference) would then be chosen. This might vary from the case where the team knows each other well and a hook-up via teleconference would be suitable to catch up on progress; to the case where the project is in real trouble and there are new people on the team, who really need to get together in one room to build team social capital. The extra expense and Carbon Footprint of a face to face meeting could be justified in the second case but not in the first.

One of the practical applications of Activity Theory is distinguishing the activity from its actions and concentrating on the purpose of the activity when making decisions and choosing tools. It suggests that people engaged in an activity will perform better along all dimensions of the triple bottom line if they are aware of and accept the activity's purpose and can concentrate on achieving the purpose with meaningful actions and tools. This is easier if subjects push as many trivial actions as possible down to the level of automated or unconscious operations using tools familiar to the subjects. Taking an activity theoretical perspective helps in finding the balance between the impact of an activity on the environment and its economic and social implications. More holistic research is needed on ways to balance face to face with online actions in distributed team activity (Hasan \& Crawford, 2006) and the appropriation of Web 2.0 and convergent media from the world of social communities into serious human enterprises (Hasan and Pfaff, 2007).

\subsubsection{Factor $2 a$ Activities producing and modelling information for more efficient and effective decision-making}

The group of five on this Factor believe that the most effective and straightforward application of IT in respect of environmental problems lie in its capability for monitoring, optimising, and modelling massive amounts of data with great speed. As can be seen in the Topic 1 column of Table 1, the majority of the group were Lecturers (permanent academic staff) with one experienced practitioner and one part-time master's student who also worked in industry. They seem to be realistic and practical on their expectations of IT capability. The activities associated with the statements that they ranked highly use a combination of primary (e.g. computational) tools and secondary (e.g. models) tools and produce large quantities of information on which decisions can be made at many levels. From the Activity Theory perspective, determining the purpose of these information generating activities is of paramount importance, otherwise they do not achieve much in themselves. How the information is used, or possibly misused, depends on other tertiary tools, such as the historical, political and social contexts that are not so straightforward as reflected in the influence of climate change sceptics. IT has been essential in supporting the scientific study, engineering and modelling of climate change and continues to do so. It is also being used to support a range of activities involving adaptive responses to threats of environmental degradation (Bedsworth and Hanak, 2010, Francisco, 2008). 


\subsubsection{Factor $2 b$ Visualising Information for advocacy and behaviour change}

This Factor has only one individual - a mature age undergraduate student - but comes out of the analysis because it is has opposing agree/disagree statements to those of Factor 2a. While the supported activities of Factor $2 \mathrm{a}$ are quite explicit, those of Factor $2 \mathrm{~b}$ are more implicit as it concerns the capability of IT to visualise information that supports more ubiquitous activities that influence human understanding and behaviour. Studies of uses of IT to visualise information that would influence behaviours were described in the Literature Review above and included, for example, the impact of sensing and displaying energy consumption and other GHS emitting events through the use of IT in the home (LeBlanc, 2007; Brush, 2007; Stringer et al., 2007). Such activities can thus complement the activities of Factor 2 a which produce the information to be visualised and act as tertiary tools that create a trigger for people to reduce their GHS emissions as they see the effect of their behaviour. Such socio-technical phenomena should fit well into Green IS.

\subsection{Topic 2}

The results of the Topic 2 analysis identify the issues and challenges to be faced in promoting and implementing the activities identified from the Topic 1. These results can be compared with some of the research mentioned in the Literature Review on the motives that influence organisational Green IT initiatives. This research (e.g. Elliot, 2007; Sayeed and Gill, 2008; Molla, 2008; Phillipson, 2009; Kuo and Dick, 2009) reports results from surveys and interviews of people in organisations. Our results come from people who have among them quite a vast experience of the IT industry from within and without. In Topic 2 of the Q-Study, their views were sought on the importance of the various issues listed in the set of statements in Table 8 to the role of IT, and the IT community, as a source of solutions to climate change problems. Their responses were varied: from issues to do with costs, jobs and regulations; to concerns about resistance to change and requirements for new forms of expertise; to genuine concern for the rights of developing nations to the same benefits from energy resources as we have had in our development. Their spread across six different Factors in the Q analysis probably is indicative of the range and balance of views held by the general public and indicates that finding consensus on where to start is not possible. Further research is needed into innovative solutions to environmental problems that use ICT in a way that accommodates the range of objectives that are embedded in initiatives to meet environmental challenges without detrimental economic and social consequences.

\section{Conclusions}

This research has sought to explore a broad range of ICT mediated activities that can potentially have positive outcomes for the environment without diminishing outcomes along the other two elements of the triple bottom line, namely economic and social. The results of this study are interesting both in terms of the Factors 1, $2 \mathrm{a}$ and $2 \mathrm{~b}$ identified in the Q-analysis of Topic 1 on the preferred technological solutions for climate change, and in terms of the confusion and lack of consensus on the importance of issues listed in Topic 2.

We contend that the established field of Green IT is limited by its focus on things (servers, monitors, desktops, networks, paper). As key publications show (Watson et al., 2010; Melville, 2010; Elliot, 2011) scoping the field of Green IS has proved more difficult. Our study shows that focussing on activities rather than things may be a fruitful way forward. The activities we have identified corresponding to the Factors coming out of Topic 1 represent three key areas of Green IS: (1) tele-working and the collaborative activities virtual teams; (2) the production and manipulation of data to produce information for decision- 
making; and (3) the visualisation of information to change behaviours. While this list may not be comprehensive it does reflect the focus of much of the Green IS literature we reviewed in Section 2 of the paper.

Regarding item (1), we have seen that there are the activities associated with working virtually that have been around for some time but have not been taken up to the extent that cost savings and flexibility would have predicted. These areas may now grow with the added drive to be more environmentally responsible, together with the increasing popularity of social technologies that enable more friendly online interaction.

Regarding item (2), we have identified obvious core IS activities where the power of IT can be used to manipulate data into information and guide informed decision making and planning.

Regarding item (3), the more creative IT-supported activities which use techniques such as visualisation to ubiquitously influence people toward greener behaviour need to be undertaken. Activities of this type could also include the innovative use of the Internet for green advocacy and the coordination of discussion on the global and local tensions concerned with environmental issues.

There are many contradictions in the outcomes of this study and other research on this topic, but this is not a problem for Activity Theory as it assumes a dialectic relationship at the heart of any meaningful collective human activity in that it is both subjective and objective. This is seen in the dual responsibilities of the IS profession where the industry has both an obligation to clean up its own act (Greening of IT) and a responsibility to ply its trade to enable others to do so (Greening by IT).

The contribution of taking an Activity Theory perspective dictates a need to evaluate the environmental impact of whole activities realising that they are not just a sum of their individual actions. In the same way, it is not automatic to scale up from local optimisations to global ones. No one group can solve the whole set of wicked environmental problems across our complex, interconnected planet earth supply chain. We should not just be content with finding ways for IT to improve the GHS emission of individual actions but seek solutions that contribute to the footprint of the whole activities in achieving their purpose. Furthermore, research studies need to increase awareness of the ways in which specific activities interact in interconnected activity systems. Many activities have multiple motives along the triple bottom line of people, profit and planet, and we should seek innovative ways by which all three are considered together in the design of sustainable ICT-mediated activities.

In presenting this analysis of issues where the IT and IS professions can use their particular knowledge and expertise in support of innovative solutions to environmental challenges, we hope that other professions are doing likewise in their respective fields. Combining the knowledge and skills of different disciplines may help clarify the confusion among the issues and challenges to be faced in promoting and implementing the activities that are responsible to the triple bottom line.

\section{References}

ACS (2007), The Australian Computer Society Policy for Green IT available at http://www.acs.org.au/acs_policies/docs/2007/greenictpolicy.pdf (accessed 21/2/2012)

Barry, J. and Proops, J. (1999), "Seeking sustainability discourses with Q methodology", Ecological Economics, Vol. 28, pp. 337-345. 
Bedsworth, L. W., and Hanak, E. (2010), "Adaptation to Climate Change," Journal of the American Planning Association, Vol. 76 No.4, pp. 477-495.

Berkhout, F and Hertin, J (2004), De-materialising and re-materialising: digital technologies and the environment, Futures, Vol. 36 No. 8, pp. 903-20.

Berthon, P. Leyland, P. And Berthon, J.P. (2008), "E-Relationships for e-Readiness: Trust \& Cultural Values in International eB2B", Industrial Marketing Management, Vol. 37, pp. 83-91.

Bose, R. and Luo, X. (2011), "Integrative framework for assessing firms' potential to undertake Green IT initiatives via virtualization - A theoretical perspective", Journal of Strategic Information Systems, Vol. 20, pp. 38-54.

Bray, R. (2007) Informative Smart Green Office Buildings, workshop in conjunction with the Ninth International Conference on Ubiquitous Computing Innsbruck,

Brush, A.J.B. (2007), "Did you leave the Calendar on?: exploring trade-offs between availability and consumption in the home," workshop in conjunction with the Ninth International Conference on Ubiquitous Computing Innsbruck

Brown, D. Dillard J. and Marshall, R.S. (2006), "Triple Bottom Line: A business metaphor for a social construct", Documents de Teball, Universitat Autonoma de Barcelona.

Brown, S.R. (1986), "Q Technique and Method: Principles and Procedures", in W.D. Berry and M.S. Lewis-Beck (Eds.), New Tools for Social Scientists, Beverly Hills, CA: Sage pp. 57-76.

Boudreau, M.-C., Chen, A. J., and Huber, M. (2008), "Green IS: Building sustainable business practices, in R. T. Watson (Ed.), Information systems Athens, GA: Global Text Project, pp. 247-261.

Caldille A and Parmigiami M (2004), "Management Information System - tool for corporate sustainability", Journal of Business Ethics, Vol. 55 No. 2 pp. 159-171.

Chen, A.J.W., Boudreau, M.C. and Watson, R.T. (2008), "Information systems and ecological sustainability", Journal of Systems and Information Technology, Vol. 10, No. 3, pp. 186-201.

CIO, (2008). "CIO's Green IT Survey: Cost Cutting, Social Responsibility Drive Environmental Moves", CIO Magazine

Daly M. and Butler T (2009), "Environmental Sustainability and Green IT: An Institutional Perspective", Proceeding of ECIS2009, Verona, Italy.

DCC, (2008), Australian Government Department of Climate Change Green Paper, Department of the Environment, Water, Heritage and the Arts http://www.climatechange.gov.au/ (accessed 21/2/2012)

Deloitte Access Economics (2011), Next Generation Telework: A Literature Review, Commonwealth of Australia, Department of Broadband, Communications and the Digital Economy, http://www. dbcde.gov.au/ (accessed 21/2/2012)

Elliot, S (2007), "Environmentally sustainable ICT: A critical topic for IS Research", Proceedings of PACIS 2007, Auckland.

Elliot, S. (2011), "Transdisciplinary Perspectives on Environmental Sustainability: A Resource Base and Framework for IT-Enabled Business Transformation," MIS Quarterly, Vol. 35 No. 1, pp. 197-236.

Elliot, A and Binney, D (2008), "Environmentally sustainable ICT: Developing corporate capabilities and an industry relevant IS research agenda", Proceedings of PACIS 2008 Suzhou China

Engeström, Y. (1987), Learning by expanding: An activity-theoretical approach to developmental research, Helsinki: Orienta-Konsultit. 
Fernandez W. Bergvall-Kareborn B. Djordjevic M. Lovegrove K. Fernandez Velasco J. and Talent M. (2008), "How IS Design can Contribute to major Climate Mitigation Projects", Proceedings of the ISF Conference, Canberra.

Francisco, H. A. (2008), "Adaptation to Climate Change," ASEAN Economic Bulletin Vol. 25 No.1, pp. 7-19.

Fuchs, C. (2008), "The implications of new information and communication technologies for sustainability", Environment, Development and Sustainability, Vol. 10 No. 3, pp. 291309.

Fuhr, J. and Pociask, S. (2007), Broadband Services: Economic and Environmental Benefits a paper for the American Consumer Institute, http://www.aci-citizenresearch.org (accessed November 2011)

Fujitsu (2011), ICT Sustainability: the Global Benchmark 2011, www.fijitsu.com/global (accessed January 2012).

Garnaut, R. (2008), Climate Change Review Final Report, http://www.garnautreview.org.au/ (accessed January 2012)

Gartner (2007), Gartner Estimates ICT Industry Accounts for 2 Percent of Global CO2 Emissions, Press Release http://www.gartner.com/it/page.jsp?id=503867 (accessed 21/2/2012)

GeSI (2008), SMART 2020 Report by GeSI and The Climate Group, http://www.gesi.org/ (accessed 21/2/2012)

Ghose, A, Hasan, H. and Spedding, T. (2008), Carbon-Centric Computing: IT Solutions for Climate Change, CCCI Report, http://ro.uow.edu.au/infopapers/669/ (accessed 21/2/2012)

Ghose, A. Hasan, H. And Spedding, T. (2009), "Carbon-centric computing - IT solutions for climate change", Telecommunications Journal of Australia, Vol 59, No. 1 pp. 9.1 to 9.12.DOI: $10.2104 / \mathrm{tja} 09009$.

Gore, A. (2006), "An Inconvenient Truth", DVD and companion book, An Inconvenient Truth: The Planetary Emergency of Global Warming and What We Can Do About It,

Hasan, H. (1998), "Activity Theory: a Basis for the Contextual Study of Information Systems in Organisations", in Hasan H, Gould E. and Hyland P. (eds) Information Systems and Activity Theory: Tools in Context Wollongong University Press. pp 19-38.

Hasan H. and Crawford K. (2006), "Demonstrations of the Activity Theory framework for Research in IS", Australasian Journal of Information Systems Vol. 13 No. 2 pp. 49-68.

Hasan, H. and Crawford, K. (2003) "A multifaceted approach to distributed communities of learning and practice", Proceedings of ISGLOB03, IFIP 8.2/9.3, Athens.

Hasan, H. Pfaff, C (2007), "Democratising Organisational Knowledge: the Potential of the Corporate Wiki", Proceedings of ICIS 2007 Montreal.

Hasbrouck, J. Igoe, T. Mankoff, J. and Woodruff, A. (2007), "Ubiquitous Sustainability: technologies for Green Value", workshop in conjunction with the Ninth International Conference on Ubiquitous Computing Innsbruck, Austria

Hooker, B. Gave, W. Steed, A and. Bowers, J. (2007), "The Pollution e-Sign", workshop in conjunction with the Ninth International Conference on Ubiquitous Computing Innsbruck.

IPCC (2012), The Fifth Assessment Report (AR5) http://ipcc.ch/ (accessed 21/2/2012).

Kaptelinin, V. (1996), “Activity Theory: Implications for Human-Computer Interaction", in B.Nardi (Ed.), Context and Consciousness: MIT Press, pp. 103-116.

Koehler, A. and Erdmann, L (2004), "Expected Environmental Impacts of Pervasive Computing", Human and Ecological Risk Assessment, Vol. 10 No. 5, pp. 831-52.

Kuo, B. and Dick, G. (2009), "The greening of the organisational IT - what makes a difference", Australasian Journal of Information Systems, Vol. 16 No. 2. 
Kuutti, K. and Virkkunen, J. (1995), "Organizational Memory and Learning Network Organization: the Case of Finnish Labour Protection Inspectors", Proceedings of HICSS-28,

LeBlanc, J. (2007), "Device-level Power consumption Monitoring”, workshop in conjunction with the Ninth International Conference on Ubiquitous Computing Innsbruck.

Leontiev, A.N. (1981), Problems of the Development of Mind, Moscow: Progress.

Ljungblad S. (2007), "Everyday Visualization to Support a sustainable Development", workshop in conjunction with the Ninth International Conference on Ubiquitous Computing, Innsbruck.

Luria, A. R. (1976) Cognitive Development, Harvard University Press, Cambridge.

McKeown, B.F. and Thomas, D.B. (1988), Q Methodology. Quantitative Applications in the Social Sciences, Newbury Park, CA: Sage.

Meloche, J and Crawford, K., (1998), "A Metaphorical Approach to Information Seeking, a Q Study", 14th Annual Conference of the Internal Society for the Scientific Study of Subjectivity, Seoul Korea.

Millecevic, M. (2007), "Imaginary To Dos: Three initiatives for personal environmental explorations", workshop in conjunction with the Ninth International Conference on Ubiquitous Computing Innsbruck.

Melville, N. P. (2010), "Information Systems Innovation for Environmental Sustainability," MIS Quarterly Vol. 34 No. 1, pp. 1-21.

Molla, A. (2008), "GITAM: A Model for the Adoption of Green IT", 19th Australasian Conference on Information Systems Christchurch, New Zealand.

Molla, A., Pittayachawan, S. and Corbitt, B. (2009), "Green IT Diffusion: An International Comparison", Green IT Working Paper Series, http://greenit.bf.rmit.edu.au/ (accessed January 2012).

Molla, A. and Licker, P (2005), "Perceived e-readiness factors in e-commerce adoption and empirical investigation in a developing country", International Journal of electronic Commerce, Vol. 10 No. 1 pp. 83-110.

Murugesan, S (2008), "Harnessing green IT: principles and practices", IT Professional Vol. 10 pp. 24-33.

Oehlberg, L. Aipperspach, R. and Jeffery, S. (2007), "Sustainability through Meaning; providing information to promote meaningful products", workshop in conjunction with the Ninth International Conference on Ubiquitous Computing Innsbruck.

Phillipson, G. (2009), Green IT in Australia 2009, Report from ConnectionResearch,

http://www.connectionresearch.com.au/_literature_32575/Green_IT_Report_Card_Overview, (accessed 20/2/2012)

Rao, O. and Holt, D. (2005), "So Green Supply Chains lead to competitiveness and economic performance", Int. Journal of Operations and Production Management, Vol. 14 No. 9 pp. 898-916.

Rittel, H. and Webber, M. (1975), "Dilemmas in a General Theory of Planning", Policy Sciences, Vol. 4, pp. 155-169.

Romm, J. Rosenfeld, A. and Herrmann, S. (1999), The Internet Economy and Global Warming; A scenario of the Impact of E-Commerce on Energy and the Environment, The Center for Energy and Climate Change Solutions, http://ww.cool-companies.org (accessed 21/2/2012).

Sayeed, L. and Gill, S. (2008), “An Exploratory Study on Environmental Sustainability and IT Use", Fourteenth Americas Conference on Information Systems (AMCIS 2008), Toronto, Canada,

Splash, C. L. (2010), "Censoring Science in Research Officially", editorial, Environmental Values, Vol. 19 No.2 pp. 141-146. 
Stephenson, W. (1953), "Postulates of Behaviorism", Philosophy of Science, Vol. 20, pp. 110 $-120$.

Stern Review (2006), The Economics of Climate Change, http://siteresources.worldbank.org/INTINDONESIA/Resources/2262711170911056314/3428109-1174614780539/SternReviewEng.pdf (accessed 20/2/2012).

Stringer, M. Fitzpatrick, G. Chalmers, D. Harris, E. Krishna, R. and Haarlander, M. (2007), "Kuckuck: Exploring ways of Sensing and Displaying Energy Consumption levels in the home", workshop in conjunction with the Ninth International Conference on Ubiquitous Computing Innsbruck, Austria.

Velte, T. Velte, A. and Elsenpeter, R (2008), Green IT: reduce your information system's environmental impact while adding to the bottom line, McGraw Hill, New York.

Verenikina, I. and Gould, E. (1998), "Cultural-Historical Psychology and Activity Theory", in Hasan H, Gould E. and Hyland P. (eds) Information Systems and Activity Theory: Tools in Context, Wollongong University Press, pp. 1-18.

Vygotsky, L.S. (1978), Mind and Society, Harvard University Press: Cambridge, MA.

Watson, R. T., Boudreau, M.-C., and Chen, A. J. (2010), "Information Systems and Environmentally Sustainable Development: Energy Informatics and New Directions for the IS Community", MIS Quarterly, Vol. 34 No. 1 pp. 23-38.

Yi L. and Thomas H. (2006), "E-business and Sustainable Development", International Journal of Environment and Sustainable Development, Vol. 5 No. 3, pp. 262-74. 
Tables and Figures:

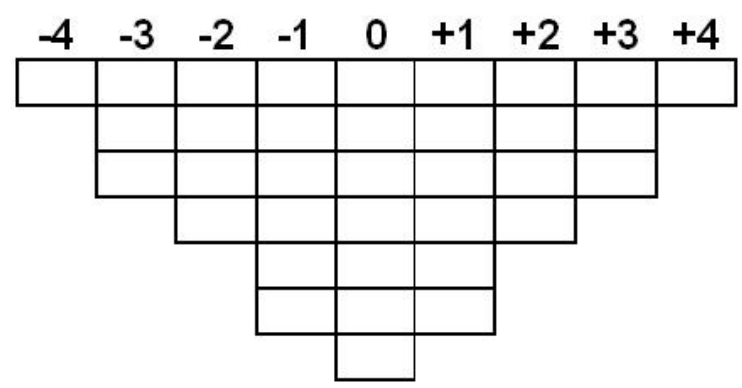

Figure 1: A Q Sort Triangle for ranking of the Statements if there were a sample of 35

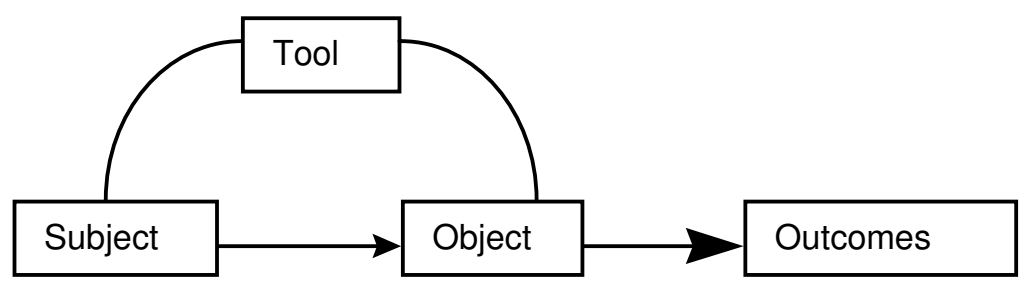

Figure 2 Tool Mediated Activity

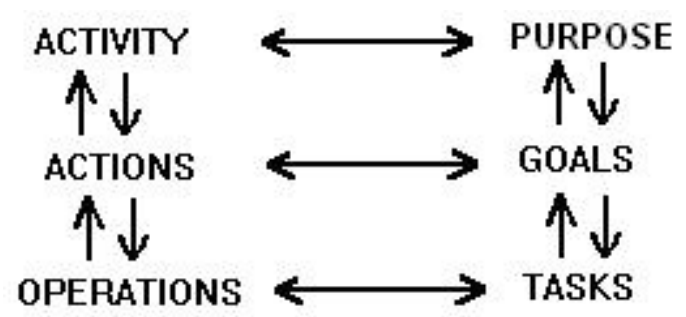

Figure 3: The Hierarchical Structure of Activity 
Table 1 Details of the 23 participants

\begin{tabular}{|r|c|c|l|l|l|}
\hline \multicolumn{1}{|l|}{ Sort \# } & Gender & Age & \multicolumn{1}{|c|}{ Position } & Topic 1 & Topic 2 \\
\hline 1 & Male & 37 & Practitioner & & \\
\hline 2 & Female & 63 & A/Professor IS & & \\
\hline 3 & Male & 57 & Lecturer & & Factor 1b \\
\hline 4 & Female & 26 & PhD Student & Factor 1 & Factor 2 \\
\hline 5 & Female & 26 & Practitioner & Factor 2a & Factor 2 \\
\hline 6 & Female & 55 & Snr Lecturer & Factor 2a & Factor 4b \\
\hline 7 & Male & 44 & PhD Student & Factor 1 & \\
\hline 8 & Male & 18 & Student & & \\
\hline 9 & Female & 24 & Practitioner & Factor 1 & Factor 1a \\
\hline 10 & Male & 62 & PhD Student & & \\
\hline 11 & Male & 35 & Student & Factor 2b & Factor 4a \\
\hline 12 & Male & 22 & PhD Student/ & & \\
\hline 13 & Male & 25 & PhD Student & Factor 1 & Factor 1a \\
\hline 14 & Male & 42 & Professor & Factor 1 & Factor 3 \\
\hline 15 & Male & 49 & Lecturer & Factor $2 \mathrm{a}$ & Factor 1a \\
\hline 16 & Male & 28 & PhD Student & Factor 1 & Factor 4a \\
\hline 17 & Male & 51 & PhD Student & Factor 1 & \\
\hline 18 & Male & 38 & Masters Student & Factor 2a & \\
\hline 19 & Male & 49 & Practitioner & & Factor 4a \\
\hline 20 & Male & 39 & Lecturer & Factor 2a & \\
\hline 21 & Male & 25 & Lecturer & & \\
\hline 22 & Male & 50 & Professor & & \\
\hline 23 & Male & 47 & A/Professor & & \\
\hline & & & & & \\
\hline
\end{tabular}

Table 2: 13 participants in 2 Factors

\begin{tabular}{c|c|c}
\hline Factor & Number of People (sorts) & Sort Numbers from Table 1 \\
\hline $\mathbf{1}$ & 7 & $4,7,9,13,14,16,17$ \\
\hline $\mathbf{2 a}$ & 5 & 1
\end{tabular}

Table 3: 14 consensus statements in the 2-Factor solution for Topic 1

\begin{tabular}{|c|c|c|c|}
\hline Statement \# & Statements & Factor 1 & Factor 2 \\
\hline 28 & Holistic business process enhancement & 2 & 1 \\
\hline 21 & Virtualization of collaborative technologies & 1 & 2 \\
\hline " & Simulation modelling for sustainable enterprises & 1 & 0 \\
\hline 27 & Guidelines for ICT procurement/purchasing & 1 & 0 \\
\hline 24 & Systems for optimization of IT quality & 0 & 1 \\
\hline 5 & Computer-based simulation & 0 & 0 \\
\hline 20 & Digital documentation readers & 0 & 0 \\
\hline 31 & e-government & -1 & 0 \\
\hline 29 & Identifying break off points for sustainable & 0 & -1 \\
\hline 10 & Digital reading systems (reducing the need for paper) & 0 & -1 \\
\hline 11 & Carbon emissions calculators & 0 & -1 \\
\hline 18 & Test and evaluate climate models & -2 & -2 \\
\hline 19 & Long-term predictions of capturing carbon from & -2 & -3 \\
\hline 16 & Global and regional climate modelling & -3 & -2 \\
\hline
\end{tabular}


Table 4: 13 participants in 4 Factors for Topic 2

\begin{tabular}{c|c|c|c|} 
Factor & Number of Ps & Ps \\
\hline $\mathbf{1 a}$ & 4 & $9,13,15,19$ \\
\hline $\mathbf{1 b}$ & 1 & 3 \\
\hline $\mathbf{2}$ & 2 & 4,5 \\
\hline $\mathbf{3}$ & 2 & 14,23 \\
\hline $\mathbf{4 a}$ & 3 & $11,16,22$ \\
\hline $\mathbf{4 b}$ & 1 & 6 \\
\hline
\end{tabular}

Table 5: 3 consensus statements in 4 Factors of Topic 2

\begin{tabular}{|c|c|c|c|c|c|}
\hline \# & Statements & Factor 1 & Factor 2 & Factor 3 & Factor 4 \\
\hline 4 & Legal issues, rules, guidelines or laws & 2 & 3 & 2 & 2 \\
\hline 6 & interpreting the science & 0 & 1 & 0 & 0 \\
\hline 28 & Legislation and taxation influencing factors & 2 & 3 & 2 & 2 \\
\hline
\end{tabular}

Table 6: A summary of the highest and lowest ranked statements of the 4 Factors of Topic 2

\begin{tabular}{|c|c|c|}
\hline & Positive Ranked Statement & Negative Ranked Statement \\
\hline $\begin{array}{l}\text { Factor 1 } \\
\text { (bipolar) }\end{array}$ & $\begin{array}{l}\text { Cost of going green; } \\
\text { Understanding Green IT investment; } \\
\text { Cost-benefit considerations; } \\
\text { Validity of carbon metrics }\end{array}$ & $\begin{array}{l}\text { Different interpretation of optimisation; } \\
\text { Reputation of advocacy groups; } \\
\text { Cultural and behavioural challenges; } \\
\text { Winning hearts and minds' }\end{array}$ \\
\hline Factor 2 & $\begin{array}{l}\text { Impact on jobs; } \\
\text { Monetary and non-monetary } \\
\text { benefits; } \\
\text { Costs of compliance to regulations; } \\
\text { Cost-benefit considerations; } \\
\text { Levels of governance; } \\
\text { Commercialisation of renewable } \\
\text { energy }\end{array}$ & $\begin{array}{l}\text { New forms of expertise - new disciplines; } \\
\text { Requiring tendering activities directly take the } \\
\text { Environmental impact of IT into } \\
\text { consideration; } \\
\text { Lack of consumer awareness; } \\
\text { Changing the traditional way in which an } \\
\text { organization does business with IT }\end{array}$ \\
\hline Factor 3 & $\begin{array}{l}\text { Rights of developing nations; } \\
\text { Ensuring environmental issues are } \\
\text { considered for new systems; } \\
\text { New forms of expertise - }\end{array}$ & $\begin{array}{l}\text { The ability to manage rapid changes in IT; } \\
\text { Leadership of professional IT associations in } \\
\text { Green IT; } \\
\text { Getting a critical mass of people to work } \\
\text { virtually }\end{array}$ \\
\hline $\begin{array}{l}\text { Factor } 4 \\
\text { (bipolar) }\end{array}$ & $\begin{array}{l}\text { Rights of developing nations; } \\
\text { Resistance to change }\end{array}$ & $\begin{array}{l}\text { Creditability of green audits; } \\
\text { The ability to manage rapid changes in IT; } \\
\text { New configurations of people, artefacts and } \\
\text { knowledge }\end{array}$ \\
\hline
\end{tabular}


Dr Helen Hasan has published extensively in Information Systems, Human Computer Interaction, Serious Games, Group Decision Support Systems, Knowledge Management, Green IS and Sensible Organisation using frameworks of Complex Activity. Helen manages an activity-based usability laboratory at the university and co-directs both the People and Organisation Research Centre and the Social Innovation Network. She has led several government-funded, cross institutional research projects and conducts industry-based consulting. She leads local, national and international special interest groups on Green IS.

Dr Joseph Meloche has a PhD in Information Systems from the University of Wollongong and is widely published in the areas of Information Seeking, Communication management, Cultural Communication, Knowledge Management, Critical Thinking, and Web Based Communication. He has a wealth of experience in Q-methodology and is President of the International Society for the Scientific Study of Subjectivity (ISSSS). 